\title{
QUANTITATIVE ECOLOGICAL RISK ASSESSMENT OF SHORTFIN MAKO SHARK (ISURUS OXYRINCHUS): PROPOSED MODEL AND APPLICATION EXAMPLE
}

\author{
DuARTE, H. O. ${ }^{1 *}$ - DroguetT, E. L. ${ }^{2}-$ MOURA, M. C. ${ }^{3}$ \\ ${ }^{I}$ Mechanical Engineering Department, Federal University of Pernambuco \\ Rua Acadêmico Hélio Ramos, $s / n$, Cidade Universitária, CTG \\ Departamento de Engenharia Mecânica, Curso de Engenharia Naval \\ 50740-530 Recife-PE, Brazil \\ (e-mail: heitorod@gmail.com; phone: +55-(81)-2126-8230; fax: +55-(81)-2126-8231) \\ ${ }^{2}$ Mechanical Engineering Department, University of Chile \\ Av. Beauchef 581, West Building, Room 411, 7630000 Santiago, Chile \\ (e-mail: elopezdroguett@ing.uchile.cl; phone: +56-9- 9545-1449; fax: +56-22-978-0861) \\ ${ }^{3}$ Production Engineering Department, Federal University of Pernambuco \\ Rua Acadêmico Hélio Ramos, s/n, Cidade Universitária, CTG \\ Departamento de Engenharia de Produção \\ 50740-530 Recife-PE, Brazil \\ (e-mail: marciocmoura@gmail.com; phone: +55-(81)-2126-7112; fax: +55-(81)-2126-8728) \\ *Corresponding author \\ e-mail: heitorod@gmail.com; phone: +55-(81)-2126-8230; fax: +55-(81)-2126-8231
}

(Received $31^{\text {st }}$ Jan 2018; accepted $2^{\text {nd }}$ May 2018)

\begin{abstract}
Most of the world's catches of sharks are incidentally taken by tuna fishing gear, constituting bycatches that increase the extinction risk of several species of shark. This not only alters ecosystem functions by removing top predators, but may also hinder the industry production itself due to cutoff measures set by authorities. This paper focuses on the female population abundance of a very important bycatch species, the shortfin mako shark (Isurus oxyrinchus), and proposes a stochastic model for quantitative risk assessment under varying harvest regimes and control measures. The proposed model can be applied to any shortfin mako shark population by changing initial conditions and harvest parameters. The flexibility of the model makes it practicable to simulate hundreds of scenarios, analyse and compare the most relevant results such as the risk of extinction caused by a given harvest regime, median time to extinction, expected minimum biomass, risk of low harvest, and risk reduction caused by control measure; these outcomes are useful for rational decisions under uncertainty. We present an application example as a means to demonstrate how the proposed model can be used to drive management decisions for sustainable tuna harvest.
\end{abstract}

Keywords: stochastic model, probabilistic systems, sensitivity analysis, monte carlo simulation, ecological modeling

\section{Introduction}

Fishes represent the only major food source still harvested from wild populations (Ryman et al., 1995). In 2014, fish harvested from aquaculture amounted an estimated first-sale value of U\$160.2 billion (FAO, 2016). Tunas and tuna-like species are an important food source, used mostly for canning and sashimi, and, because of their high economic value and extensive international trade, are an important global commodity. The total catch of tuna and tuna-like species was about 7.4 million tons, representing $9 \%$ of the global catch in 2013. Tuna fishing is undertaken by thousands of vessels in 
the Pacific, Indian and Atlantic oceans, using a range of gear types (e.g., longline) (Clarke, 2008; FAO, 2016; Gilman and Lundin, 2008; Hamilton et al., 2011).

Most of the world's catches of sharks are incidentally taken by various types of tuna fishing gear, constituting bycatch that is either discarded at sea (without fins or dead) or landed for sale (Carvalho et al., 2011). Bycatches increase the risk of extinction of several species of shark and alters ecosystem functions by removing top predators (Myers and Baum, 2007). Moreover, bycatches cause economical risk to the industry because of conservation limits set by the International Commission for the Conservation of Atlantic Tunas (ICCAT), i.e., a cutoff threshold at which fishing should stop, often set at $20 \%$ of the unfished equilibrium abundance of relevant species such as the mako shark (Smith et al., 1993). In other words, if mako shark population declines more than $80 \%$ of its unfished equilibrium abundance, tunas' harvest must be forbidden. Thus, we focus here on a shark species mainly because there has been increasing concern about the status of some shark stocks and the population-level effects caused by their exploitation (Anon, 2009, 2013; Carvalho et al., 2011; FAO, 1999; Myers and Baum, 2007).

The adult shortfin mako shark (SMA) (Isurus oxyrinchus) is an apex predator at the top of the marine environment food web and it is not a prey to any marine animal. These sharks are long lived, slow growing, reach sexual maturity late in their life history, and produce few offspring (Levesque, 2007). They have a common total length of $270 \mathrm{~cm}$, maximum total length of $445 \mathrm{~cm}$ (Weigmann, 2016), maximum published weight of 50.,8 kgs and maximum reported age of 32 years (Natanson et al., 2006).

This work focuses on the SMA for several reasons (Anon, 2009, 2013; CosandeyGodin and Morgan, 2011; Levesque, 2007): (i) its relatively high abundance and presence in multiple and widespread fisheries; (ii) it is captured in great numbers in all oceans and ranks as one of the most dominant species caught in pelagic longlines and gillnets; (iii) it is considered an apex predator at the top of the marine environment food web; (iv) female SMAs are being caught below the size of maturity; (v) unlike most shark species, the SMA is economically important due to both its quality of meat and fins; (vi) it is a valuable product of the pelagic longline swordfish and tuna fisheries; (vii) failures in conservation management of SMA can be significant and costly.

Therefore, we propose a stochastic population model for Quantitative Ecological Risk Assessment (QERA) of SMA bycatch that results from the industrial tuna fishing. Our model is a useful tool for both conservation of SMA and the sustainable management of tuna industry. Moreover, it is capable of describing the dynamics of SMA population under varying conditions (harvest regime and control measures), for evaluating the role of such conditions, and for producing meaningful conclusions that can be used to drive conservation and management decisions. The model is thought to be generic so that it can be applied to any SMA population (e.g., South Atlantic, North Atlantic, North Pacific) by making minor changes in parameters and initial conditions.

We exemplify the application of the model for the SMA South Atlantic population and describe means of evaluating risk of extinction and yield associated with alternative decisions about harvest rates and cutoff threshold. The methodology, used for QERA in both the model building and application example, is similar to the approach used in (Duarte et al., 2013, 2014; Duarte and Droguett, 2015), but here it is specifically tailored for solving the SMA case.

The remainder of the paper is organized as follows. First, we provide a brief literature review. Second, we propose a model structure to describe the dynamics of the 
system in any ocean. Next, by means of an application example, we demonstrate how to conduct a QERA of SMA bycatch implied by tuna fishing based on the proposed model. Finally, we conclude remarks by presenting the model benefits and shortcomings.

\section{Materials and Methods}

\section{Literature Review}

Even though the SMA is physiologically unique, economically important, and exploited in relatively large numbers (Levesque, 2007), there are few population models for this species (Anon, 2009, 2013). These approaches aimed at diagnosing the population status over the last 30 years by quantifying measures such as past and current biomass, and abundance. Conversely, we aim at describing the population dynamics under varying scenarios over time so that the proposed model can be a useful tool for rational decisions under uncertainty.

There are some applications of stochastic models for risk assessment of marine fish (Duarte et al., 2013; Fu et al., 2004; Hart and Cadrin, 2004; Smedbol and Stephenson, 2004) that have the goal of describing the population dynamics over time and under predefined conditions by using past data for estimating the model parameters and setting the initial conditions. They include uncertainty in parameters, and thus results are given in terms of probability. However, at the best of authors' knowledge, there is no such approach tailored for mako shark populations.

Yet, our modelling approach is similar to the two models of herring (Fu et al., 2004; Smedbol and Stephenson, 2004) in the following aspects: (i) it evaluates the risk of extinction caused by harvest; (ii) includes uncertainty in parameters; (iii) has the flexibility to include a cutoff measure; and (iv) includes low-frequency events that may cause recruitment failure, which occurs when individuals at age 0 (pups) have poor survival due to hypothetical events such as pollution, construction or any human impact in breeding areas on the coast; or environmentally induced recruitment failure such as hurricanes, earthquakes, tsunamis. The specific cause of recruitment failure remains a mystery and there is no research about its effects in SMA, but we assume recruitment failure may also occur with SMA as happens with other marine fishes (Payne et al., 2009; Smedbol and Stephenson, 2004).

In spite of the similarities, our approach departs from the abovementioned works in the following aspects: (i) the proposed model describes a population of a shark species, which is the utmost difference because sharks and herrings have remarkably different life histories; (ii) it models females only; (iii) it measures uncertainty about the future harvest regime through a plausible range of scenarios; and (iv) it evaluates the risk caused by conservative scenarios of harvest regime (Levesque, 2007). Then, in the next section, we present the characteristics of the proposed model.

\section{The Proposed Model}

The proposed model only considers females because they are a key indicator to control. In fact, females produce new individuals and keep the life cycle on. Thus, keeping track of females is more effective to evaluate extinction risk. Furthermore, most available data are given only for females, probably because of the same aforementioned reason. Thus, hereafter, "population", if not specified, refers to "female population". 
Then, the purpose of the model is to describe the SMA female abundance over 100 years under varying conditions. Indeed, we consider: (i) a benchmark scenario (Scn-0) that simulates the natural population dynamics under no harvest; (ii) varying harvest scenarios with different harvest parameters and (iii) harvest scenarios with and without a cutoff threshold for which no harvest occurs if abundance falls below it.

Now, let $N_{i}(t)$ be the abundance of females in stage $i ; N$ the total abundance of female population; $s_{i}$ the survival rate (per year) of females in stage $i ; p_{i}$ the permanence rate (per year) of females in stage $i ; f$ the fecundity rate (pups per year); $a_{i j}$ the transition rate (per year) from stage $j$ to stage $i$, where $i$ is the line and $j$ the column in the matrix; $h_{i}$ is the harvest rate for stage $i ; N^{\text {cutoff }}$ is the abundance threshold for cutoff; and $F^{r f}$ is the frequency per year that recruitment failure occurs. Note that $a_{10}=s_{0} ; p_{1}=s_{1}-a_{21} ; p_{2}=s_{2}-a_{32} ;$ and $p_{3}=s_{3}$. Then, the algorithm described below constitutes our proposed generic model for SMA female abundance that can be parameterized to describe the dynamics of the system in any ocean. It represents one replication for simulating the population model and involves the following steps:

i) If $N<K$, then make

$$
\left[\begin{array}{c}
N_{0}(t+1) \\
N_{1}(t+1) \\
N_{2}(t+1) \\
N_{3}(t+1)
\end{array}\right]=\left[\begin{array}{cccc}
0 & 0 & f & 0 \\
a_{10} & p_{1} & 0 & 0 \\
0 & a_{21} & p_{2} & 0 \\
0 & 0 & a_{32} & p_{3}
\end{array}\right]\left[\begin{array}{l}
N_{0}(t) \\
N_{1}(t) \\
N_{2}(t) \\
N_{3}(t)
\end{array}\right]
$$

If $N>N^{\text {cutoff }}$, then make

$$
\left[\begin{array}{l}
N_{0}(t+1) \\
N_{1}(t+1) \\
N_{2}(t+1) \\
N_{3}(t+1)
\end{array}\right]=\left[\begin{array}{l}
N_{0}(t+1) \\
N_{1}(t+1) \\
N_{2}(t+1) \\
N_{3}(t+1)
\end{array}\right] \cdot\left[\begin{array}{l}
1-h_{0} \\
1-h_{1} \\
1-h_{2} \\
1-h_{3}
\end{array}\right]
$$

ii) Otherwise:

$$
\left[\begin{array}{l}
N_{0}(t+1) \\
N_{1}(t+1) \\
N_{2}(t+1) \\
N_{3}(t+1)
\end{array}\right]=[K]\left[\begin{array}{l}
0.169 \\
0.678 \\
0.086 \\
0.068
\end{array}\right]
$$

iii)Generate random number $U$ from a uniform distribution.

If $\mathrm{U}<F^{r f}$, then

$$
\left[\begin{array}{c}
N_{0}(t+1) \\
N_{1}(t+1) \\
N_{2}(t+1) \\
N_{3}(t+1)
\end{array}\right]=\left[\begin{array}{l}
N_{0}(t+1) \\
N_{1}(t+1) \\
N_{2}(t+1) \\
N_{3}(t+1)
\end{array}\right] *\left[\begin{array}{c}
M^{r f} \\
1 \\
1 \\
1
\end{array}\right]
$$

Table 1 defines the model variables, parameters and initial conditions. The estimation of parameters and the setting of initial conditions will be explained in next 
sections. Eq. 1 is a Lefkovitch matrix (Lefkovitch, 1965), which describes the natural dynamics of the population. We consider a four-stage structure for SMA population: pups, juveniles, mature adults, and post-reproductive adults. Eq. 2 models the effect of harvest, which was considered in the simulation to reflect stage selectivity by the fishery. Note that harvest strategies do not affect survival rates. Instead, for each scenario, harvest was included by removing a certain proportion of the stage-specific population every year, and a cutoff threshold was included to simulate a control measure in which no harvest occurs if the abundance declines belowthat limit. Eq. 3 describes the Density Dependence (DD) effect, which represents a change in the influence of any factor that affects population growth as the population density changes (Forbes et al., 2010; Pauwels, 2002). The constants in Eq. 3 refer to the steady-state population distribution, i.e., the proportion of individuals in each stage $(16.9 \%$ age 0 , $67.8 \%$ juveniles, $8.6 \%$ mature adults and $6.8 \%$ post-reproductive adults) when the population dynamics reach a stationary state, which is based only on the stage matrix for Scn-0 and is a result of eigenvalue analysis. For more details, see references (Akçakaya et al., 1997; Akçakaya and Root, 2013; Burgman et al., 1993). Finally, Eq. 4 allows to include known and/or suspected variations in vital rates (survival and fecundity) caused by low-frequency, high-consequence events such as recruitment failure. This is modelled via Bernoulli trials (Burgman et al., 2012).

Note that, although the proposed model structure is thought to be generic, it can be tailored to incorporate many realistic and case-specific features such as: (i) a stagestructured SMA population (pups, juveniles, mature adults, and post-reproductive adults); (ii) stage-specific initial abundance; (iii) uncertainty in parameters such as survival and fecundity; (iv) Density Denpendency; (v) low-frequency events that may cause recruitment failure; (vi) stage-specific annual harvest as a proportion of the stagespecific abundance; and (vii) cutoff threshold for which no harvest occurs if abundance is below it.

The four stages (pups, juveniles, mature adults, and post-reproductive adults) considered for female individuals in the population are structured based on characteristics such as weight, survival, fecundity and harvest rate. A summary of the female SMA life history in our model is as follows (Fig. 1) (Levesque, 2007). Pups (stage 0 ) are born at age 0 . Those who survive until age 1 become juveniles (stage 1 ). The juveniles, who survive until the age of 19-21, reach maturity and become mature adults (stage 2). Mature adults who survive produce new pups until the age of 25-27 years, when they reach sexual mortality and become post-reproductive adults (stage 3 ). Post-reproductive adults naturally die at an average age of 32 years. By doing so, we can project the stage-specific population abundance using a Lefkovitch matrix (also known as Stage matrix) (Lefkovitch, 1965).

The model also considers DD. Authors of fish case studies (Fu et al., 2004; Smedbol and Stephenson, 2004) had reported difficulty for estimating the DD parameters. Most assumed Ceiling-type DD (Akçakaya et al., 1999), according to which, on one hand, vital rates are not affected until the population reaches the carrying capacity $K$ that is the level of abundance above which population tends to decline. On the other hand, other types of DD increase vital rates at low density. Thus, Ceiling-type DD is more conservative to assess extinction because production of new individuals is likely to be underestimated at low density and, hence, the risk of extinction will be overestimated (Burgman et al., 1993). 


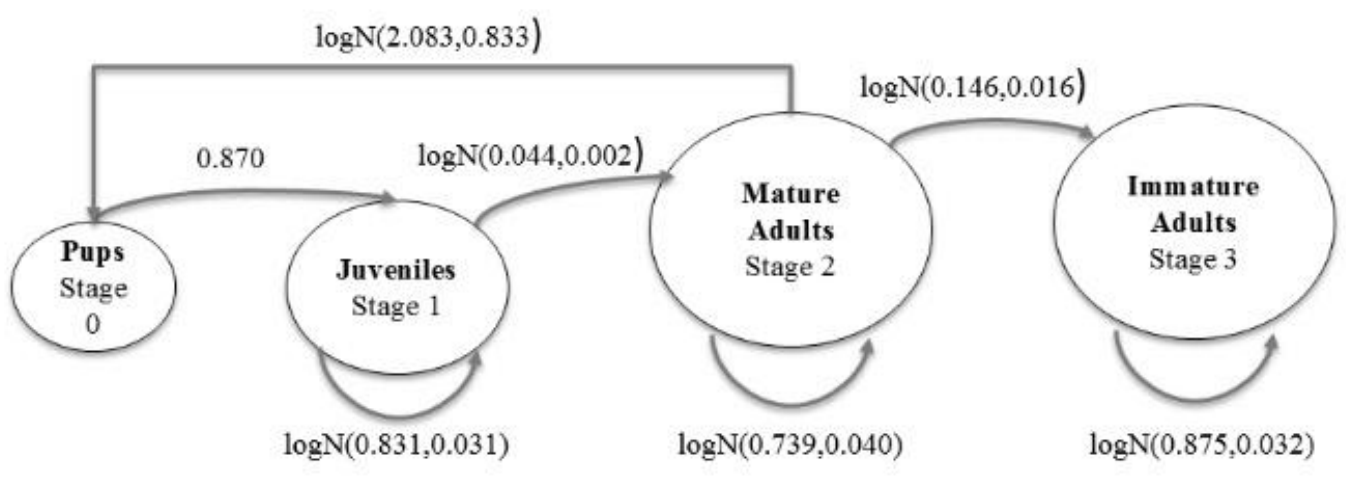

Figure 1. Female SMA life cycle. The values above the arrows are estimates for transition and permanence rates

Then, our model also assumes Ceiling-type DD. If the population significantly grows so that it reaches $K$, then it remains at that level until the population decreases below this level. In this case, $K$ acts as a population ceiling (Akçakaya et al., 1999). These conditions are modeled in the first and second steps of the algorithm.

The proposed model also includes uncertainty. The effect of parameter uncertainty on outcomes can be bounded by fitting a Probability Distribution Function (PDF) (e.g., Normal or Lognormal) to each parameter chosen from their average, lower and upper values. For a given scenario, one should define initial conditions and fit a PDF to each parameter using data, literature information, and/or expert opinion. After that, a chosen number of replications of the model (say 10,000) can be simulated via Monte Carlo approach (Kalos and Whitlock, 2008). For a given scenario, the result is a dataset of abundances, $N_{i}(t)$, for each stage $i$ and for each time-step $t$. From such dataset, the following summarized outputs can be provided:

- PDFs for the proportion of abundance decline within 100 years.

- Cumulative Distribution Functions (CDFs) for the time to quasi-extinction (i.e., $80 \%$ population decline) within 100 years.

- point estimates originated from either the PDFs or CDFs, i.e.:

$\circ$ year-specific risk of quasi-extinction (i.e., probability of $80 \%$ abundance decline).

- median time to quasi-extinction.

- expected minimum abundance (i.e., an estimate of the smallest population size that is expected to occur within 100 years).

$\circ$ expected total harvest weight at the end of simulation.

$\circ$ year-specific risk of low harvest (i.e., the probability that the annual harvest will be at or below a threshold measure).

For the same population, one can conduct a sensitivity analysis of harvest scenarios and control measures by varying parameters such as $h_{i}$ and $N^{\text {cutoff }}$, while keeping all other parameters the same. For example, by keeping all other parameters the same as in Scn-0 and varying parameters related to harvest, we aim at evaluating the added/reduced risk caused by each harvest scenario. Likewise, by keeping all other parameters the same and varying the cutoff threshold, we aim to assess the reduced risk caused by this limit that is, in fact, a control measure to satisfy conservation objectives. 
Thus, the proposed model provides the following outputs: risk categories and ranking of scenarios for better risk communication to stakeholders; the quantified reduced risk caused by varying control measures; suggest harvest regime that not only reduces conservation concerns, but also achieves maximal benefits by increasing yield over the long term at acceptable risk of low harvest.

\section{Application Example}

We conduct an application example and parameterize the proposed model to the South Atlantic Ocean. The next subsections are useful as a guide on how to apply the model and interpret results. The outcomes are useful to validate the model, yet they should not be used to drive real political decisions with regard to conservation of SMA since data are still uncertain. However, in the future, with more accurate SMA catch data available, a new round of scenarios can be simulated and the outcomes may be used for this purpose.

\section{Materials and Data Sources}

Data used here are gathered from several public sources. Estimates of parameters related to the harvest distribution of stages and sex were obtained from onboard observer's data provided under request by the Brazilian Ministry of Fisheries and Aquaculture. An onboard observer after each set filled out the logbooks. Data included individual records of 33 vessels in the South Atlantic that registered 241,776 SMAs catches between December/2004 and February/2009. Useful information to this work also considered: the vessel identification, onboard observer identification, date, location of fishing ground (latitude and longitude), effort (number of hooks), fork length $(\mathrm{cm})$ and sex (male, female or not available).

To transform data given in terms of fork length into weight or age and the inverse, we use the length-weight correlation (Kohler and Casey, 1995) (Eq. 5) and the 3parameter Gompertz growth function for SMA, (Natanson, 2002) (Eq. 6), which produced the most biologically reasonable estimates for females.

$$
W T=5.2432 \times 10^{-6} \times(L)^{3.1407}
$$

where: WT $=$ Total weight; $\mathrm{L}=$ Fork length (i.e., the length of a fish measured from the tip of the snout to the end of the middle caudal fin rays and is used in fishes in which it is difficult to inform where the vertebral column ends (Froese and Pauly, 2011)).

$$
L(t)=L_{0} e^{G\left(1-e^{(t-k t)}\right)} \text { and } G=\ln L_{\infty} / L_{0}
$$

where: $\mathrm{t}$ is the age (years); $L_{0}=88 \mathrm{~cm} ; L_{\infty}=366 \mathrm{~cm}$; and $k=0.087$ year $^{-1}$.

From the female total catches, only 7,359 had their fork length measured so that we transform fork length into age, then into stage, and calculate (respectively for age 0 , juvenile, mature adult and post-reproductive adult) the annual catch percentage for each stage $i, A C_{\tilde{i}}$, as $5.95 \%, 92.21 \%, 0.38 \%$ and $1.46 \%$ and the average weight in $\mathrm{kg}$ of each stage as $6.7,113.9,329.5,417.2$. Thus, stage-specific harvest rates are estimated for a specific scenario as follows: 


$$
h_{i}=\frac{\text { (population harvest rate per year for the specifie scenario }) \times \sum_{\gamma i} N_{i}(0) \times A C_{i}}{N_{i}(0)}
$$

Bycatch of SMAs results in substantial number of SMAs being discarded dead. Quantifying total harvest from bycatch is challenging because comprehensive data on these discards are unavailable (Cosandey-Godin and Morgan, 2011). Then, we assume that mortality of SMAs is greater than catch estimates (Anon, 2013) for two reasons. Indeed, estimates may not include uncertainty about (i) post-release mortality (Cosandey-Godin and Morgan, 2011; Gilman et al., 2008), and (ii) the catches of sharks that were illegally discarded at sea to make space for tunas in the freezers.

Estimates of initial abundance and carrying capacity were obtained from a stock assessment conducted by ICCAT (Anon, 2013) and estimates of parameters related to the ecology and population dynamics (i.e., natural mortality, age and growth, reproduction, stage-specific life span, age at first maturity, age-weight) were gathered from literature. Table 1 describes the model parameters and their source of information. For the cases, where there is more than one source for the same parameter, we assume the one with widest confidence interval in order to be more conservative. Note that for the Carrying Capacity parameter, to extrapolate data that do not differentiate sex (Anon, 2013) into females only data, we consider the common male:female ratio in the population that is equal to 1 (Garcia-Cortes and Mejuto, 2002).

We adopted software RAMAS Metapop v.6.0 (Akçakaya and Root, 2013). This software is a computational tool for population model construction and probabilistic simulation via Monte Carlo methods (Kalos and Whitlock, 2008).

\section{Parameters, Uncertainty and Error}

Table 1 presents the parameters $\omega$ governing the dynamics of the system. They were given either as a mean value $\bar{\omega}$ or as a triplet $\left(\omega_{L}, \bar{\omega}, \omega_{U}\right)$, which represents lower, mean and upper values. For the latter case, we consider the parameters have a truncated normal distribution and that the error $\left(\max \left\{\bar{\omega}-\omega_{L}, \omega_{U}-\bar{\omega}, 0.5\left(\omega_{U}-\omega_{L}\right)\right\}\right)$ corresponds to a $3 \sigma$ interval; thus, such parameters will be randomly selected to fall between their limits in $99.865 \%$ of replications.

It is believed that one can make good use of a Gaussian approach in vital rates because there is a reasonable reason for random values not to be too far away from the average, i.e., there are biological limitations preventing very large deviations and natural forces of equilibrium bringing vital rates back to their average values (Taleb, 2007). For probabilistic simulation, the RAMAS software converts the normal distribution of vital rates into a corresponding lognormal distribution. This conversion avoids bias resulting from truncation because $\omega \geq 0$ (Burgman et al., 1993; Ferson and Akçakaya, 1990).

We assume that the population is exposed each year to a $10 \%$ probability of recruitment failure (i.e., $F^{r f}=0.1 /$ year - Eq. 4) that decreases stage 0 abundance to $5 \%$ of the value expected if such event had not occurred. Carrying capacity (K) was estimated (Table 1) based on the population biomass provided by the stock assessment as 956,777 mt (from Scenario-6 in reference (Anon, 2013)) under virgin conditions, i.e., the current population abundance if there was no fishing. Most simulation scenarios included annual harvest that prevented abundance from reaching the ceiling defined by $\mathrm{K}$. 
Table 1. Definition of variables and parameters. The discrete time unit is 1 year

\begin{tabular}{|c|c|c|c|c|c|}
\hline $\begin{array}{l}\text { Variable, Parameter or } \\
\text { Initial condition }\end{array}$ & Symbol & Description and assumptions & Mean & Max and/or Min & SD \\
\hline $\begin{array}{l}\text { Number of female SMA at } \\
\text { time } t\end{array}$ & $N(t)$ & $\begin{array}{l}\text { Assessment endpoint. Population abundance } \\
\text { at time } t \text {. The sum of the number of females } \\
\text { in all stages. }\end{array}$ & & & \\
\hline $\begin{array}{c}\text { Number of female SMA in } \\
\text { stage } i \text { at time } t\end{array}$ & $N_{i}(t)$ & Abundance of female SMA at stage $i$. & & & \\
\hline $\begin{array}{c}\text { Transition rate from stage } 0 \text { to } \\
\text { stage } 1 \text { (per year) }\end{array}$ & $a_{10}$ & Survival of age 0 class (0.87) (Anon, 2013). & 0.87 & & \\
\hline $\begin{array}{l}\text { Permanence rate in stage } 1 \\
\text { (per year) }\end{array}$ & $p_{1}$ & $\begin{array}{l}\text { Annual survival rate for age } 1+\text { (i.e., } 1 \text { year } \\
\text { or more) is in the range of } 0.78-0.97 \text { (Anon, } \\
2013) \text {, thus we assume mean }=0.875 \text {. } \\
\text { Median }(50 \% \text { ) age at maturity for females is } \\
\text { in the range of } 19-21 \text { years (Bishop et al., } \\
\text { 2006), thus we assume mean = } 20 \text { years. }\end{array}$ & $\begin{array}{c}=0.875^{*}(20-1) / 20= \\
0.831\end{array}$ & $\begin{array}{c}\operatorname{Max}=0.97 *(21-1) / 21= \\
0.924 ; \\
\operatorname{Min}=0.78 *(19-1) / 19= \\
0.739\end{array}$ & $\begin{array}{c}=(0.924- \\
0.739) / 6= \\
0.031\end{array}$ \\
\hline $\begin{array}{c}\text { Transition rate from stage } 1 \text { to } \\
\text { stage } 2 \text { (per year) }\end{array}$ & $a_{21}$ & $\begin{array}{l}\text { Annual survival rate for age } 1+\text { is in the } \\
\text { range of } 0.78-0.97 \text { (Anon, 2013), thus we } \\
\text { assume mean }=0.785 \text {. } \\
\text { Median (50\%) age at maturity for females is } \\
\text { in the range of } 19-21 \text { years (Bishop et al., } \\
\text { 2006), thus we assume mean }=20 .\end{array}$ & $=0.875 / 20=0.044$ & $\operatorname{Max}=0.97 / 19=0.051$ & $\begin{array}{c}=(0.051- \\
0.044) / 3= \\
0.002\end{array}$ \\
\hline $\begin{array}{l}\text { Permanence rate in stage } 2 \\
\text { (per year) }\end{array}$ & $p_{2}$ & $\begin{array}{l}\text { Annual survival rate for age } 1+\text { is in the } \\
\text { range of } 0.78-0.97 \text { (Anon, 2013), thus we } \\
\text { assume mean }=0.875 \text {. } \\
\text { Age that female SMA reach sexual mortality } \\
\text { is within the range of } 25-27 \text { years (Stevens, } \\
\text { 1983), thus we assume mean }=26 \text {. } \\
\text { Average duration in stage } 2=26-20=6 \\
\text { years. } \\
\text { Max duration in stage } 2=27-19=8 \text { years. }\end{array}$ & $\begin{array}{c}=0.875 *(6-1) / 6= \\
0.729\end{array}$ & $\begin{array}{c}\operatorname{Max}=0.97 *(8-1) / 8= \\
0.849\end{array}$ & $\begin{array}{c}=(0.849- \\
0.729) / 3= \\
0.04\end{array}$ \\
\hline
\end{tabular}




\begin{tabular}{|c|c|c|c|c|c|}
\hline $\begin{array}{c}\text { Variable, Parameter or } \\
\text { Initial condition }\end{array}$ & Symbol & Description and assumptions & Mean & Max and/or Min & SD \\
\hline $\begin{array}{c}\text { Fecundity rate from stage } 2 \text { to } \\
0 \text { (per year) }\end{array}$ & $f$ & $\begin{array}{c}\text { Litter size ranges from } 4 \text { to } 27.5 \text { and mean } \\
\text { litter size is } 12.5 \text { (Mollet et al., 2000). } \\
\text { Reproductive periodicity ( } 3 \text { years) (Anon, } \\
2013 \text { ). } \\
\text { Probability of producing a female pup }=0.5 \text {. }\end{array}$ & $\begin{array}{c}=(12.5 / 3) * 0.5= \\
2.083\end{array}$ & $\begin{aligned} \operatorname{Max}= & (27.5 / 3) * 0.5= \\
& 4.583\end{aligned}$ & $\begin{array}{c}=(4.583- \\
2.083) / 3= \\
0.833\end{array}$ \\
\hline $\begin{array}{c}\text { Transition rate from stage } 2 \text { to } \\
\text { stage } 3 \text { (per year) }\end{array}$ & $a_{32}$ & $\begin{array}{l}\text { Annual survival rate for age } 1+\text { is in the } \\
\text { range of } 0.78-0.97 \text { (Anon, 2013). } \\
\text { Age that female SMA reaches sexual } \\
\text { mortality is within the range of } 25-27 \text { years } \\
\text { (Stevens, 1983). } \\
\text { Average duration in stage } 2=26-20=6 \\
\text { years. } \\
\text { Max duration in stage } 2=27-19 .\end{array}$ & $=0.875 / 6=0.146$ & $\operatorname{Min}=0.78 / 8=0.098$ & $\begin{array}{c}=(0.146- \\
0.098) / 3= \\
0.016\end{array}$ \\
\hline $\begin{array}{l}\text { Permanence rate in stage } 3 \\
\text { (per year) }\end{array}$ & $P_{a}$ & $\begin{array}{c}\text { Annual survival rate for age } 1+\text { is in the } \\
\text { range of } 0.78-0.97 \text {, mean }=0.875 \text { (Anon, } \\
2013) .\end{array}$ & 0.875 & $\operatorname{Max}=0.97$ & $\begin{array}{c}=(0.970- \\
0.875) / 3= \\
0.032\end{array}$ \\
\hline Carrying Capacity & $K$ & $\begin{array}{l}\text { The SMA biomass under virgin conditions } \\
(956,777,000 \mathrm{~kg}) \text { (from S6, Table 19, Anon } \\
\text { (2013)) } \\
\text { Sex ratio in the population (1 female: } 1 \\
\text { male) (Garcia-Cortes and Mejuto, 2002) } \\
\text { Female SMA mean weight (205.031 kg) } \\
\text { (from length-weight correlation and growth } \\
\text { function in Materials and Data Sources } \\
\text { section). }\end{array}$ & $\begin{array}{c}= \\
(956,777,000 / 205.03 \\
1)^{*} 0.5=2,333,248\end{array}$ & & \\
\hline $\begin{array}{l}\text { Population cutoff/quasi- } \\
\text { extinction threshold }\end{array}$ & $N^{\text {cutoff }}$ & $\begin{array}{l}\text { Unfished equilibrium abundance }(2,333,248) \\
\text { (Anon, 2013). } \\
\text { Cutoff threshold is often set at } 20 \% \text { of } \\
\text { unfished equilibrium abundance (Smith et } \\
\text { al., 1993). }\end{array}$ & $\begin{array}{c}=2,333,248 * 0.2= \\
466,650\end{array}$ & & \\
\hline $\begin{array}{l}\text { Frequency (per year) of } \\
\text { recruitment failure }\end{array}$ & $F^{v f}$ & $\begin{array}{l}\text { Based on population models of other marine } \\
\text { fishes (Payne et al., 2009; Smedbol and } \\
\text { Stephenson, 2004). }\end{array}$ & 0.1 & & \\
\hline
\end{tabular}




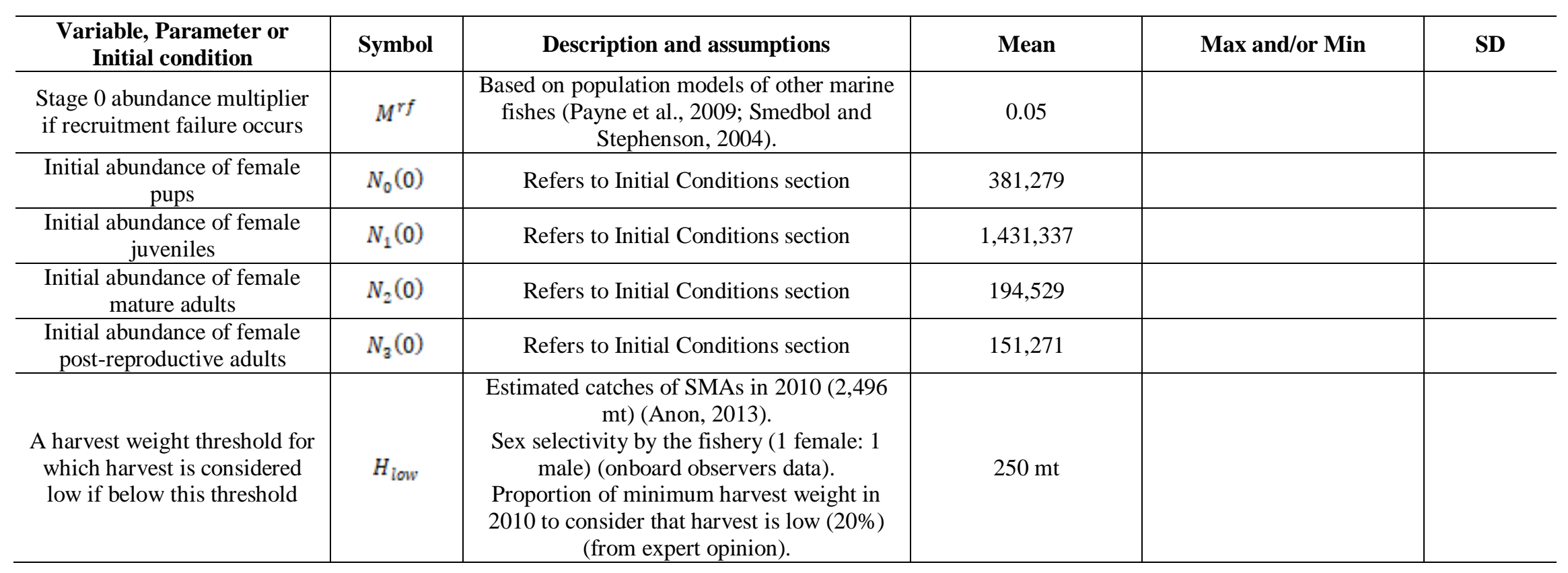




\section{Initial Conditions}

First, we estimate the initial population abundance from the stock assessment by ICCAT (Anon, 2013), which simulated 13 scenarios with varying parameters and provided the SMA biomass in 2010 as result of each simulation. We consider the effect of uncertainty in initial biomass by using the result of the scenario with the lowest value, i.e., 885,085 $\mathrm{mt}$ from Scenario-6, Table 19 (Anon, 2013). Next, we assume the initial stage distribution is equal to the steady stage distribution in $E q$. 3; this results in the initial conditions in Table 1.

\section{Harvest Scenarios}

The real number of SMA catches is uncertain. The landing data only show known catches, but the unknown catches (e.g., illegal discards at sea) may be even greater than the known ones. As suggested by (Taylor et al., 2002), the effect of parameter uncertainty on outcomes can be considered by consolidating scenarios with parameters chosen from the range of plausibility. We interviewed an onboard observer and data monitor that worked in a tuna longline vessel that had capacity to stock 200 tons of fish meat. From that discussion, we deliberated a range of playsibility for real catches, i.e., we assumed real catches are not smaller than Catch Estimates (CE) in 2010 and not greater than thirty-two times CE. We simulated hundreds of harvest scenarios by varying catch paremeters whitin this range of plausibility. For the sake of illustration, Table 2 only presents the parameters of six scenarios that we thought are the most relevant to present in this work. We selected these scenarios for presentations purpose for the following reasons: $S \mathrm{cn}-0$ is a base scenario that reflects natural population growth without any bycatch; Scn-CE is one extreme in the range of plausability which reflects catch estimates without unknown bycatches; Scn-4 is another extreme that reflects total catches (known and unknown) being thirty-two times greater than CE; and Scn-1. Scn-2, Scn-3 are well spaced intermediate scenarios withint the range of plausibility in which total catches are, respectively, four, seven and twenty-one times greater than CE.

Table 2. Harvest parameters

\begin{tabular}{c|c|c|c|c|c|c}
\hline Harvest scenario & Scn-0 & Scn-CE & Scn-1 & Scn-2 & Scn-3 & Scn-4 \\
\hline Total harvest per year & 0 & $0.29 \%$ & $1 \%$ & $2 \%$ & $6 \%$ & $9 \%$ \\
\hline$h_{0}$ & 0 & $0.10 \%$ & $0.34 \%$ & $0.67 \%$ & $2.02 \%$ & $3.03 \%$ \\
\hline$h_{1}$ & 0 & $0.40 \%$ & $1.39 \%$ & $2.87 \%$ & $8.34 \%$ & $12.51 \%$ \\
\hline$h_{2}$ & 0 & $0.01 \%$ & $0.04 \%$ & $0.08 \%$ & $0.25 \%$ & $0.38 \%$ \\
\hline$h_{3}$ & 0 & $0.06 \%$ & $0.21 \%$ & $0.41 \%$ & $1.24 \%$ & $1.87 \%$ \\
\hline $\begin{array}{c}\text { Number of female } \\
\text { catches at first year }\end{array}$ & 0 & 6,259 & 21,584 & 43,168 & 129,505 & 194,257 \\
\hline $\begin{array}{c}\text { Number of times that } \\
\text { simulated catches are } \\
\text { greater than catch } \\
\text { estimates } \\
\text { (Anon, 2013) }\end{array}$ & 0 & 1 & 4 & 7 & 21 & 32 \\
\hline \begin{tabular}{c} 
(Antimen \\
\hline
\end{tabular} & & & & & & \\
\hline
\end{tabular}

By simulating Scn-0, we aim at evaluating the natural population dynamics, quantify its background risk and the added risk caused by all relevant scenarios when compared to it. By simulating Scn-CE, Scn-1, Scn-2, Scn-3 and Scn-4 we aim at propagating the 
effect of uncertainty about real catches. We also simulate all harvest scenarios with and without cutoff in order to evaluate the maximum reduced risk caused by this management threshold that is, in fact, a control measure to comply conservation objectives.

\section{Risk Categories}

By categorizing risks, results can be better interpreted by risk managers, society, and other interested parties. We use the risk categories proposed by (Duarte et al., 2013, 2014; Duarte and Droguett, 2015). It is important to note that the following categories are more conservative than the International Union for Conservation of Nature (IUCN) categories (IUCN, 2001). The latter are used to classify species affected by a whole range of environmental changes and human disturbance at regional (IUCN, 2003) or global-levels, whereas the former is proposed to classify risks caused by a single stressor (harvest) to a single population, which is our case.

- CRITICALLY ENDANGERED (CR): more than 50\% additional probability of quasi-extinction within 3 generations (i.e., median time to quasi-extinction is shorter than 3 generations).

- ENDANGERED (EN): more than $20 \%$ additional probability of quasiextinction within 5 generations.

- VULNERABLE (VU): more than $10 \%$ additional probability of quasiextinction within 5 generations.

- NEGLIGIBLE (NE): less than 10\% additional probability of quasi-extinction within 5 generations.

We assume that female SMAs have a generation time of 20 years (Froese and Pauly, 2011) and harvest scenarios that cause NE risks are considered sustainable.

\section{Results and Discussion}

Fig. 2 illustrates how female SMA average abundance in the South Atlantic varies over time (100 years) for several harvest scenarios (Scn-0, Scn-CE, Scn-1, Scn-2, Scn-3 and Scn-4, respectively, 0\%, 0.29\%, 1\%, 2\%,6\% and $9 \%$ of the population removed every year). The Scn-0 curve represents the population dynamics if no fishing occurs. Scn-0 curve is superimposed on Scn-CE, which shows the abundance trajectory if real catches were as described by landing data. The abundance reaches a dynamic equilibrium at the carrying capacity, which is around 2,33E+6.

Note that population growth rate when unfished (Scn-0) is almost nil and the same happens to Scn-CE. Obviously, the population abundance for Scn-CE is overestimated because landing data do not consider unkown bycatches discarded at sea. Catch estimates from landing data is so optimistic that, for practical purposes, the population dynamics under these catch estimates (Scn-CE) is the same as under no fishing (Scn-0). Nonetheless, Scn-CE is a positive scenario that is presented to highlight model accuracy.

Because of the great uncertainty about real catches, we also consider Scn-3 or Scn-4 (6\% or $9 \%$ annual harvest, respectively), which show overfishing situations in which the population rapidly declines to, respectively, 1,260,764 (258,496 $\mathrm{mt})$ and 519,322 $(106,477 \mathrm{mt})$ females. Scn-3 causes an additional 10.6\% risk of quasi-extinction within 5 generations; then, it is classified as VU, whereas Scn-4 causes $56.2 \%$ probability of 
quasi-extinction within 3 generations; thus, it is categorized as CR. These two scenarios simulate more conservative situations, but, given the great importance of SMA to the ecosystem, it is worth dealing with uncertainty in this way. In the case of more accurate SMA catch data being available in the future, interpretation of results may change.

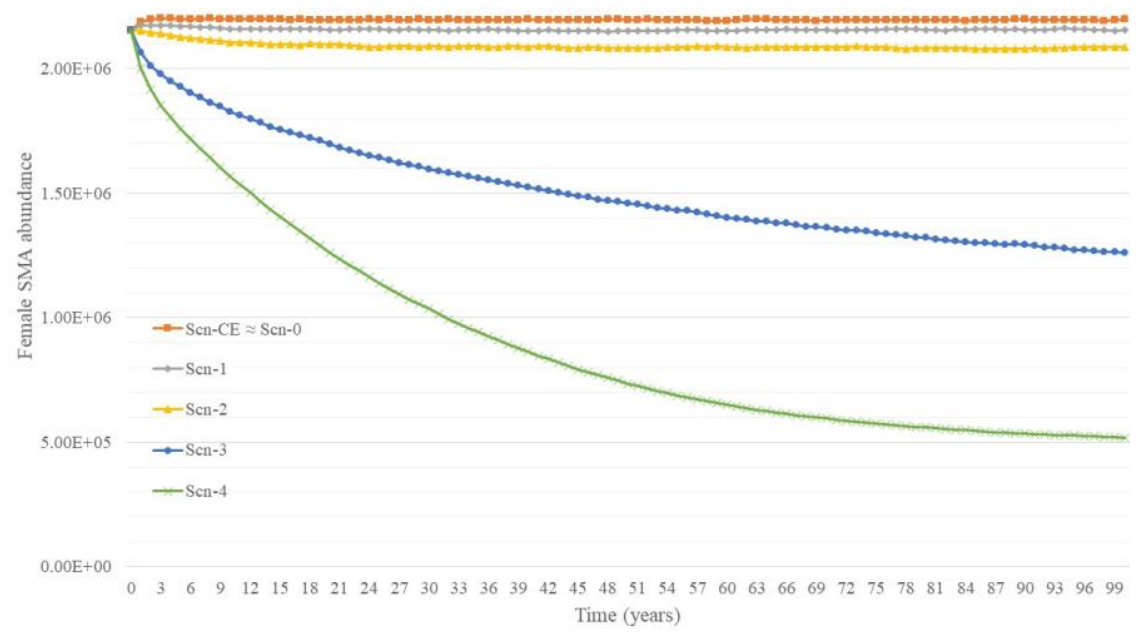

Figure 2. Female SMA average abundance for relevant scenarios.

Table 3 summarizes the main results for each harvest scenario. Values with a + or symbol mean that they are being compared to the benchmark Scn-0, except for the maximum effect of cutoff measure, which is compared against the same scenario without cutoff. The risk of harvest scenarios is indicated both as additional risk of quasiextinction compared to Scn-0 and as reduced expected minimum abundance also related to Scn-0. The median time to quasi-extinction is calculated from the CDF for the time that the population size will fall below the quasi-extinction threshold. Only Scn-4 had the median of its distribution shorter than 100 years, i.e., $50 \%$ probability of quasiextinction within 56 years. All other scenarios had less than $50 \%$ probability of quasiextinction within 100 years.

Table 2. Risk results

\begin{tabular}{c|c|c|c|c|c|c}
\hline Harvest scenario & Scn-0 & Scn-CE & Scn-1 & Scn-2 & Scn-3 & Scn-4 \\
\hline $\begin{array}{c}\text { Risk of quasi- } \\
\text { extinction }\end{array}$ & 0 & 0 & 0 & 0 & +0.106 & +0.878 \\
\hline $\begin{array}{c}\text { Risk category } \\
\text { to quasi-extinction }\end{array}$ & $>100$ & $>100$ & $>100$ & $>100$ & $>100$ & 56 \\
\hline $\begin{array}{c}\text { Expected minimum } \\
\text { biomass (mt) }\end{array}$ & 332,785 & 327,778 & 316,081 & 297,773 & 170,477 & 80,731 \\
\hline $\begin{array}{c}\text { Maximum effect of } \\
\text { cutoff measure }\end{array}$ & $\begin{array}{c}\text { Not } \\
\text { applicable }\end{array}$ & $\begin{array}{c}\text { Not } \\
\text { significant }\end{array}$ & $\begin{array}{c}\text { Not } \\
\text { significant }\end{array}$ & $\begin{array}{c}\text { Not } \\
\text { significant }\end{array}$ & $\begin{array}{c}-0.057 \text { risk } \\
\text { of } 83 \% \\
\text { population } \\
\text { decline }\end{array}$ & $\begin{array}{c}-0.721 \text { risk } \\
\text { of } 87 \% \\
\text { population } \\
\text { decline }\end{array}$ \\
\hline $\begin{array}{c}\text { Expected yield } \\
\text { (total harvest weight } \\
\text { (mt)) }\end{array}$ & $\begin{array}{c}\text { Not } \\
\text { applicable }\end{array}$ & 73,660 & 241,554 & 469,821 & $\begin{array}{c}1,000,000 \\
886,045\end{array}$ \\
\hline $\begin{array}{c}\text { Risk of low harvest } \\
\text { ( } \leq 250 \text { mt) }\end{array}$ & $\begin{array}{c}\text { Not } \\
\text { applicable }\end{array}$ & 0 & 0 & 0 & 0.132 & 0.887 \\
\hline
\end{tabular}




\section{The Effect of the Cutoff Threshold Measure}

We quantify the maximum effect caused by the cutoff management threshold. The maximum effect of cutoff is measured as the maximum reduced risk for a scenario with and without cutoff. The reported number is the Kolmogorov-Smirnov test statistic D, which is the maximum vertical difference between risk curves, based on a two sample Kolmogorov-Smirnov test (Akçakaya and Root, 2013). The approximate location (point $\mathrm{X}$ at which maximum reduced risk occurs, i.e., percentage of decline) is also given.

Thus, we simulate all harvest scenarios with and without cutoff, compare their risk of population decline and measure the maximum reduced risk and the point at which it occurs (Table 3). For Scn-4, the cutoff measure reduces $72 \%$ the risk of $87 \%$ population decline, whereas for Scn-3, it reduces $5.7 \%$ the risk of $83 \%$ population decline. For all other scenarios, risk reduction is insignificant.

\section{Harvest Results}

The yield of SMA is not only important as a secondary product, but also as an indicator for yield of tuna, since SMA are bycatched by various types of tuna and tunalike fishing gear. Thus, changes in SMA harvest means proportional changes in tuna harvest. The number of SMA catches as a proportion of tuna catches depends on several specific factors such as the vessel fishing gear and fishing grounds. Thus, the vessel interested in how the presented SMA harvest results impact their yield of tuna should make their own estimates.

Fig. 3 shows, for each harvest scenario, the expected total weight of harvest as a function of time. The harvest is calculated based on the average weight of each stage (see Materials and Data Sources section). Scn-0 is not applicable here since it is not a yielding scenario. Total harvest for 100 years of simulation and risk of low harvest are presented in Table 3.

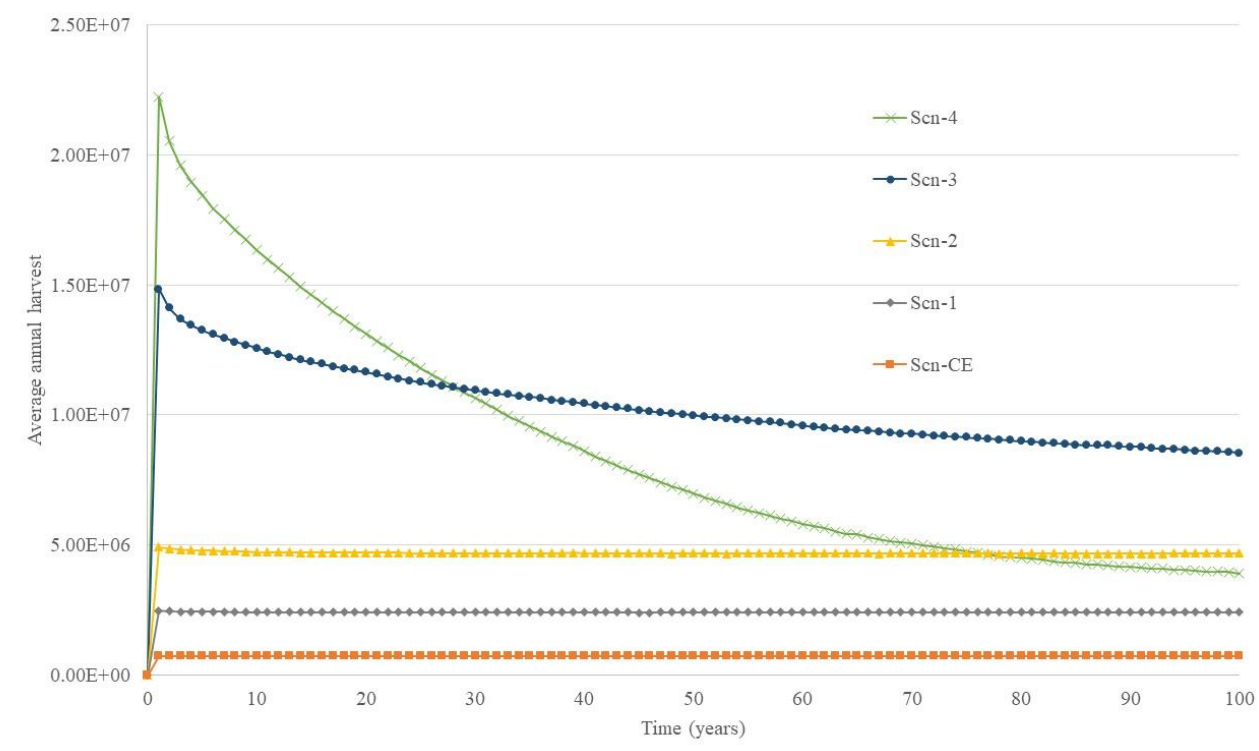

Figure 3. Average weight of female SMA harvest as a function of time for each harvest scenario (Scn-CE, Scn-1, Scn-2, Scn-3 and Scn-4) 
It is worth focusing on Scn-3 or Scn-4 to deal with uncertainty because of inaccurate SMA catch data. These scenarios are not good for both conservation and production because: (i) they are not sustainable, i.e., Scn-3 is categorized as VE and Scn-4 as CR; (ii) although Scn-3 maximizes yield, it causes a considerable risk of low harvest (13\%); and (iii) Scn-4 does not provide maximum yield and risk of low harvest is significantly high (89\%).

\section{Conclusions}

This paper dealt with a very important bycatch species of worldwide tuna fisheries. Its capture is of major conservation concern, thus this subject is of great interest and relevance for pelagic fisheries and their management. Yet, the methodology to approach the problem is innovative because it is capable of: (i) quantifying the added risk of extinction caused by harvest scenarios and the reduced risk caused by cutoff measures; (ii) dealing with uncertainty; (iii) including low frequency events; and (iv) quantifying risk of low harvest.

The proposed model can be applied to any SMA population by changing initial conditions and harvest parameters. We conducted QERA for the SMA South Atlantic population in order to exemplify the application of the model and consistent results were obtained.

The model is most useful for risk managers as an aid for rational decisions about harvest regimes under uncertainty. The flexibility of the model made it practicable to simulate and evaluate hundreds of scenarios and analyze their results. The risk results of relevant scenarios were transformed into risk categories for easier communication to stakeholders. The model also allowed for update of parameters as new data become available. Companies interested in sustainable production can thus register data of SMA bycatch and use them as an input for the model.

For the application example, great uncertainty on input data also caused great uncertainty in results. Without accurate SMA catch data, which is caused for example by unknown illegal discards, uncertainty about the real scenario is great. Consequently, risk results for SMA quasi-extinction varies from categories NE to CR.In this sense, we recommend future studies that can reduce data uncertanty, e.g.: improving the current methods for data monitoring onboard; new data gathering methods other than the traditional onboard observer (e.g., fin trade data); and new statistical approaches for catch estimates (e.g., bayesian statistics). In this way, our proposed model can be used to simulate less uncertain scenarios in order to aid decision makers. For now, the application example described in this article only works for the sake of illustration.

Acknowledgements. Thanks to the Coordination of Improvement of Higher Level Personnel (CAPES) Ministry of Education of Brazil, for the Sandwich Doctorate grant number 99999.012371/2013-00; and to Alan Salazar, an observer onboard of a tuna longline vessel.

\section{REFERENCES}

[1] Akçakaya, H. R., Burgman, M. A., Ginzburg, L. R. (1997): Applied Population Ecology: Principles and Computer Exercises Using RAMAS EcoLab 2.0. - Applied Biomathmatics, Setautek, New York. 
[2] Akçakaya, H. R., Burgman, M. A., Ginzburg, L. R. (1999): Applied Population Ecology. (2nd ed.) - Sinauer Associates, Sunderland, Massachussets.

[3] Akçakaya, H. R., Root, W. T. (2013): RAMAS GIS: Linking Spatial Data with Population Viability Analysis (Version 6). - Applied Biomathematics, Setauket, New York.

[4] Anon (2009): Report of the 2008 Shark Stock Assessment Meeting (Madrid, Spain, September 1 to 5, 2008). - Collect. Vol. Sci. Pap. ICCAT 64(5): 1343-1491.

[5] Anon (2013): Report of the 2012 Shortfin Mako Stock Assessment and Ecological Risk Assessment Meeting (Olhao, Portugal - June 11-18, 2012). - Collect. Vol. Sci. Pap. ICCAT 69(4): 1427-1570.

[6] Bishop, S., Francis, M., Duffy, C., Montgomery, J. (2006): Age, growth, maturity, logevity and natural mortality of the shorfin mako (Isurus oxyrinchus) in New Zealand waters. - Mar. Freshwater Res. 57: 143-154.

[7] Burgman, M. A., Ferson, S., Akçakaya, H. R. (1993): Risk Assessment in Conservation Biology. - Chapman and Hall, London.

[8] Burgman, M. A., Franklin, J., Hayes, K. R., Hosack, G. R., Peters, G.W., Sisson, S. A. (2012): Modeling Extreme Risks in Ecology. - Risk Analysis 32(11): 1956-1966.

[9] Carvalho, F. C., Murie, D. J., Hazin, F. H. V., Hazin, H. G., Leite-Mourato, B., Travassos, P., Burgess, G. H. (2011): Catch rates and size composition of blue sharks (Prionace glauca) caught by the Brazilian pelagic longline fleet in the southwestern Atlantic Ocean. - Aquat. Living Resour. 23: 373-385.

[10] Clarke, P. (2008): Management of Tuna Fisheries in the Western and Central Pacific. IUCN Environmental Policy and Law Paper 72(11).

[11] Cosandey-Godin, A., Morgan, A. (2011): Fisheries Bycatch of Sharks: Options for Mitigation. - Ocean Science Division, Pew Environment Group, Washington, DC.

[12] Duarte, H. O., Droguett, E. L. (2015): Quantitative Ecological Risk Assessment of accidental oil spills on ship routes nearby a marine national park in Brazil. - Human and Ecological Risk Assessment: An International Journal, Taylor \& Francis 22(2): 350-368.

[13] Duarte, H. O., Droguett, E. L., Araújo, M., Teixeira, S. F. (2013): Quantitative Ecological Risk Assessment of Industrial Accidents: The Case of Oil Ship Transportation in the Coastal Tropical Area of Northeastern Brazil. - Hum. Ecol. Risk Assess., Taylor \& Francis 19(6): 1457-1476.

[14] Duarte, H. O., Droguett, E. L., Moura, M. das C., de Souza Gomes, E. C., Barbosa, C., Barbosa, V., Araújo, M. (2014): An Ecological Model for Quantitative Risk Assessment for Schistosomiasis: The Case of a Patchy Environment in the Coastal Tropical Area of Northeastern Brazil. - Risk Analysis 34(5): 831-846.

[15] FAO (1999). International Plan of Action for the Conservation and Management of Sharks, Food and Agricultre Organization of the United Nations, Rome.

[16] FAO (2016). The state of world fisheries and aquaculture. The State of World Fisheries and Aquaculture 2016, p. 160.

[17] Ferson, S., Akçakaya, H. R. (1990): RAMAS/age User Manual: Modeling Fluctuations in Age-Structured Populations. - Applied Biomathematics, New York.

[18] Forbes, V. E., Calow, P., Grimm, V., Hayashi, T., Jager, T., Palmqvist, A., Pastorok, R. (2010): Integrating population modeling into ecological risk assessment. - Integr. Environ. Assess. Manage. 6(1): 191-193.

[19] Froese, R., Pauly, D. (2011): Fishbase. - World Wide Web eletronic publication. www.fishbase.org, version 08/2011.

[20] Fu, C., Wood, C. C., Schweigert, J. (2004): Pacific Herring (Clupea pallasi) in Canada: Generic Framework for Evaluating Conservation Limits and Harvest Strategies. - In: Akçakaya, H. R., Burgman, M. A., Kindvall, O., Wood, C. C., Hatfield, J. S., McCarthy, 
M. A. (eds.) Species Conservation and Management: Case Studies, Oxford University Press, New York, USA.

[21] Garcia-Cortes, B., Mejuto, J. (2002): Size-weight relationship of the swordfish (Xiphias gladius) and several pelagic shark species caught in the Spanish surface longlinse fishery in the Atantic, Indian and Pacific Oceans. - ICCAT (Int. Comm. Conserv. Atl. Tunas) Coll. Vol. Sci. Pap. 54(4): 1132-1149.

[22] Gilman, E., Clarke, S., Brothers, N., Alfaroshigueto, J., Mandelman, J., Mangel, J., Petersen, S. (2008): Shark interactions in pelagic longline fisheries. - Marine Policy 32: $1-18$.

[23] Gilman, E. L., Lundin, C. G. (2008): Minimizing Bycatch of Sensitive Species Groups in Marine Capture Fisheries: Lessons from Commercial Tuna Fisheries. - In: Grafton, Q., Hillborn, R., Squires, D., Tait, M., Williams, M. (eds.) Handbook of Marine Fisheries Conservation and Management, Oxford Univesity Press, Oxford.

[24] Hamilton, A., Lewis, A., McCoy, M. A., Havice, E., Campling, L. (2011): Market and Industry Dynamics in the Global Tuna Supply Chain. - FFA, European Union.

[25] Hart, D. R., Cadrin, S. X. (2004): Yellowtail Flounder (Limanda ferruginea) off the Northeastern United States. - In: Akçakaya, H. R., Burgman, M. A., Kindvall, O., Wood, C. C., Hatfield, J. S., McCarthy, M. A. (eds.) Species Conservation and Management: Case Studies. Oxford University Press, New York, USA.

[26] IUCN (2001). IUCN Red List Categories: Version 3.1. IUCN Species Survival Comission, Gland, Switzerland and Cambridge, UK.

[27] IUCN (2003). Guidelines for Application of IUCN Red List Criteria at Regional Levels: Version 3.0., IUCN Species Survival Comission, Gland, Switzerland and Cambridge, UK.

[28] Kalos, M. H., Whitlock, P. A. (2008): Monte Carlo Methods. - Wiley-VCH, Weinheim.

[29] Kohler, N. E., Casey, J. G. (1995): Lenght-weight associations for 13 species of sharks from the western North Atlantic. - Fish. Bull. 93: 412-418.

[30] Lefkovitch, L. P. (1965): The study of population growth in organisms grouped by stages. - Biometrics 21: 1-18.

[31] Levesque, J. C. (2007): A Comprehensive Review of the Biology and Preliminary Investigation of Interactions with the U.S. Pelagic Longline Fishery for the Shortfin (Isurus Oxyrinchus) and Longfin (Isurus Paucus) Mako Sharks. - Oceanographic Center, Nova Southeastern University.

[32] Mollet, H. F., Cliff, G., Pratt, H. L. J., Stevens, J. D. (2000): Reproductive biology of the female shortfin mako, Isurus oxyrinchus Rafinesque, 1810, with comments on the embryonic development of lamnoids. - Fish. Bull. 98: 299-318.

[33] Myers, R. A., Baum, J. K. (2007): Cascading effects of the loss of apex predatory sharks from a coastal ocean. - Science 315: 1850-1946.

[34] Natanson, L. J. (2002): Preliminary investigations into the age and growth of the shortfin mako shark, Isurus oxyinchus, white shark, Carcharodon carcharias, and thresher shark, Alopias vulpinus, in the western North Atlantic Ocean. - Coll. Vol. Sci. Pap. 54(4): 1280-1293.

[35] Natanson, L. J., Kohler, N. E., Ardizzone, D., Cailliet, G. M., Wintner, S. P., Mollet, H. F. (2006): Validated age and growth estimates for the shortfin mako, Isurus oxyrinchus, in the North Atlantic Ocean. - Environmental Biology of Fishes 77(3-4): 367-383.

[36] Pauwels, S. J. (2002): Fish Population Modeling: Data Needs and Case Study. - In: Pastorok, R.A., Bartell, S.M., Ferson, S., Ginzburg, L.R. (eds.) Ecological Modeling in Risk Assessment: Chemical Effects on Populations, Ecosystems and Landscapes, CRC Press LLC, Boca Raton, FL. 
[37] Payne, M. R., Hatfield, E. M. C., Dickey-Collas, M., Falkenhaug, T., Gallego, A., Groger, J., Licandro, P. (2009): Recruitment in a changing environment: the 2000s North Sea herring recruitment failure. - ICES J. Mar. Sci. 66: 272-277.

[38] Ryman, N., Utter, F., Laikre, L. (1995): Protection of intraspecific biodiversity of exploited fishes. - Rev.: Methods Technol. Fish Biol. Fish. 5: 417-446.

[39] Smedbol, R. K., Stephenson, R. L. (2004): Atlantic Herring (Clupea harengus) in the Northwest Atlantic Ocean: dynamics of nested population components under several harvest regimes. - In: Akçakaya, H. R., Burgman, M. A., Kindvall, O., Wood, C. C., Hatfield, J. S., McCarthy, M. A. (eds.) Species Conservation and Management: Case Studies, Oxford University Press, New York, USA.

[40] Smith, S. J., Hunt, J. J., Rivard, D. (1993): Risk Evaluation and Biological Reference Points for Fisheries Management. - Canadian Special Publication of Fisheries and Aquatic Sciences No. 120, Fisheries and Oceans Canada, Ottawa.

[41] Stevens, J. D. (1983): Observations on the reproduction in the shorftin mako, Isurus oxyrinchus. - Copeia 1: 126-130.

[42] Taleb, N. N. (2007): The Black Swan: The Impact of the Highly Improbable. - Random House \& Penguin, Paris.

[43] Taylor, B. L., Wade, P. R., Ramakrishnan, U., Gilpin, M., Akçakaya, H. (2002): Incorporating uncertainty in population viability analyses for the purpose of classifying species by risk. - In: Beissinger, S. R., McCullough, D. R. (eds.) Population Viability Analysis, University of Chicago Press, Chicago.

[44] Weigmann, S. (2016): Annotated checklist of the living sharks, batoids and chimaeras (Chondrichthyes) of the world, with a focus on biogeographical diversity. - Journal of Fish Biology 88(3): 837-1037. 